\title{
Influence of the powder/liquid ratio on the properties of zinc oxide-eugenol-based root canal sealers
}

\author{
J. Camps*, L. Pommel, F. Bukiet, I. About \\ U.F.R Odontologie, Universite' Me'diterrane'e, 27 boulevard Jean Moulin, Marseille cedex 5 13385,
}

France

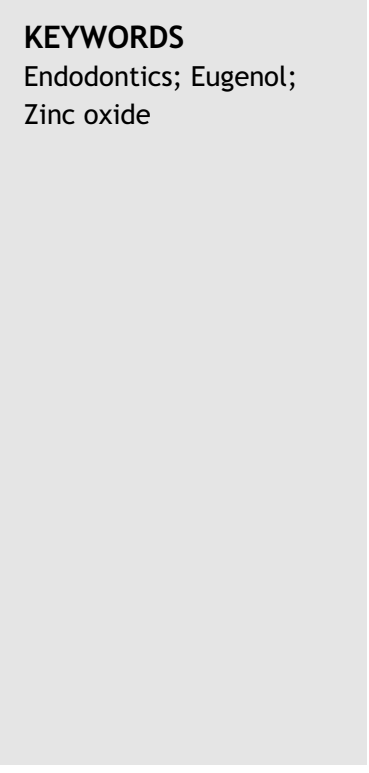

\begin{abstract}
Summary Objective: The purpose of this study was to investigate the effects of modifications of the powder/liquid ratio by endodontists on the physical properties recommended by ISO standards as well as on other clinically relevant properties of zinc oxide-eugenol-based root canal sealers.

Methods: The powder/liquid ratio of two zinc oxide-eugenol-based root canal sealers (Cortisomol and Pulp Canal Sealer EWT) was recorded by 10 endodontists. The materials, prepared according to the different consistencies, were tested according to ISO standards to evaluate their physical properties. Their sealing efficiency and the release of eugenol were also evaluated on 20 single rooted teeth.

Results: Some results varied according to the material. Nevertheless, for both cements, an increased powder/liquid ratio led to a decreased flow, an increased radiopacity and a decreased amount of eugenol released. The variations in the powder/liquid ratio did not influence the dimensional changes and the apical leakage of both cements.

Significance: Variations in the powder/liquid ratio of zinc oxide-eugenol-based root canal sealers have a limited influence on the properties of the sealers. The endodontists can prepare the zinc oxide-eugenol-based root canal sealers at their chosen consistency according to the filling technique they use.
\end{abstract}

\section{Introduction}

Zinc oxide-eugenol-based cements are the most commonly used root canal sealers. Eugenol, which is the main constituent of oil of cloves, is weakly ionised and has a dimeric structure with both interand intra-molecular hydrogen bonds [1]. Zinc oxide is a base that can be prepared in three different ways; from oxidation of the metal; by direct decomposition of the zinc ores in air; or by thermal decomposition of zinc compounds [2]. Mixed together, the setting reaction of zinc oxideeugenol is a classical acid-base reaction giving a salt plus water [3]. Zinc oxide plus a small amount of water gives zinc hydroxide, which in turn, with eugenol, gives zinc eugenolate plus water that returns to catalyse the reaction. During the reaction, the phenolic hydrogen ions are replaced by zinc ions, forming zinc eugenolate, which is a weak 
chelate [1]. Unlike zinc phosphate cements, this setting reaction is weakly exothermic [4].

Calculation from the setting equation shows that, after setting, the root canal sealer is not suitable for clinical purposes. Two molecules of eugenol ( $\mathrm{mw} 164)$ react with one molecule of zinc oxide ( $\mathrm{mw}$ 81) resulting in a flowable root canal sealer. Endodontists generally use a much higher powder/liquid ratio leading to the formation of a crystallite zinc eugenolate matrix that encases zinc oxide powder grains that have not been used in the reaction [5]. The weakness of this cement is attributed to the poor interconnections between the zinc-oxide particles and the matrix, associated with a voided structure [5].

The endodontists adjust the powder/liquid ratio of the zinc oxide-eugenol root canal sealers in order to obtain what each considers to be the most desirable consistency [6]. A study including several endodontists showed that the powder/ liquid ratio may vary from 2 to 4 for the same root canal sealer. Since some essential properties, such as disintegration [7] and setting time [8] are under the control of the powder/liquid ratio of the zinc oxide-eugenol-based sealers, preparing the root canal sealer with a varying consistency may result in variations in the properties of the set root canal sealer. This may have clinical consequences.

The purpose of this work was to evaluate the effects of the powder/liquid ratio on the properties of two commercially available zinc oxide-eugenolbased root canal sealers.

\section{Materials and methods}

\section{The root canal sealers}

Two zinc oxide-eugenol-based root canal sealers were used for this study, one based on the Rickert Formula and one based on the Grossman formula [9]:

\section{The powder/liquid ratio}

Ten endodontists participated in the study. For each root canal sealer, the vials of powder and liquid were weighed with a precision scale (Ohaus, NJ, USA). A drop of liquid was then placed onto a glass slab and the endodontist was asked to prepare the root canal sealer according to his chosen consistency. The vials were then weighed a second time to determine the amount of powder and liquid each endodontist used for the mixture. The same experiment was done by each of the 10 endodontists and the results averaged.

This allowed us to obtain three powder/liquid ratios for the Cortisomol: liquid, medium and thick consistency and two powder/liquid ratios for the Pulp Canal Sealer EWT because of a lower discrepancy in the results: medium and high consistency.

All of the following experiments were done five times, for the two root canal sealers and the five consistencies.

\section{The ISO standard properties (ISO 6876) ${ }^{10}$}

\section{Flow}

The root canal sealers were mixed according to the above conditions, and $0.05 \pm 0.005 \mathrm{ml}$ of sealer was placed on the centre of a glass plate with a graduated syringe. After $3 \mathrm{~min}$, a second glass plate weighing $120 \mathrm{~g}$ was placed on the sealer. After seven additional minutes, the diameter of the disc of sealer was recorded in $\mathrm{mm}$.

\section{Working time}

The same experiment was repeated but at increasing intervals of time between the root canal sealer mixing and the superposition of the second glass slab. The working time was recorded when the disc diameter was $10 \%$ less than the value previously recorded.

\section{Setting time}

Root canal sealer specimens $(10 \mathrm{~mm}$ in diameter and $1 \mathrm{~mm}$ high) were prepared and stored in

\begin{tabular}{lllc}
\hline & Powder & Liquid & Batch number \\
\hline $\begin{array}{l}\text { Pulp Canal Sealer } \\
\text { EWT (Kerr, Romulus, }\end{array}$ & $\begin{array}{l}\text { Zinc oxide silver } \\
\text { resin thymol iodide }\end{array}$ & Eugenol Canada balsam & $2-1350$ \\
$\begin{array}{l}\text { Cortisomol (Pierre } \\
\text { Rolland, Merignac, }\end{array}$ & $\begin{array}{l}\text { Zinc oxide lead } \\
\text { oxide paraformaldehyde }\end{array}$ & Eugenol & $3-145$ \\
\hline
\end{tabular}


an incubator at $37{ }^{\circ} \mathrm{C}$ and $95 \%$ humidity. An indenter $(100 \pm 0.5 \mathrm{~g})$ with a flat end $(2 \mathrm{~mm}$ in diameter $)$ was repeatedly lowered vertically onto the surface of the sealer. The mixing time was recorded when no indentation could be detected.

\section{Film thickness}

The combined thickness of two glass slabs was measured with a micrometer (Leica, Nussloch, Germany) with a $1 \mu \mathrm{m}$ accuracy. The root canal sealer was prepared and $0.05 \pm 0.005 \mathrm{ml}$ were deposited onto the first glass plate. After $3 \mathrm{~min}$, the second plate was placed and a load of $150 \mathrm{~N}$ was applied. After seven additional minutes, the thickness of the glass slabs plus the sealer was recorded.

\section{Dimensional changes}

Root canal sealer specimens, $12 \mathrm{~mm}$ high and $6 \mathrm{~mm}$ in diameter were prepared using split cylindrical molds. Two grams of the root canal sealer were prepared with $0.02 \mathrm{~g}$ of water and were poured into the molds. The excess was removed and a glass slab was placed under and on the mold to obtain two flat surfaces. The specimens were allowed to set at $37{ }^{\circ} \mathrm{C}$ and $95 \%$ humidity for $24 \mathrm{~h}$. After setting the surfaces were polished with 600,800 and 1200 grit wet sandpaper. The height of each specimen was measured. The specimens were stored in distilled water at $37^{\circ} \mathrm{C}$ for 30 days before remeasuring their height.

\section{Solubility}

Root canal sealer samples $(20 \mathrm{~mm}$ in diameter and $1 \mathrm{~mm}$ high) were prepared mixing $2 \mathrm{~g}$ of root canal sealer with $0.02 \mathrm{~g}$ of water. Split-ring molds were filled with the root canal sealer and the excess removed. Two glass plates were placed under and on the mold to obtain flat surfaces. The samples were stored for $24 \mathrm{~h}$ in an incubator at $37^{\circ} \mathrm{C}$ and $95 \%$ humidity to set. The weight of each sample, as well as the weight of the glass Petri dish, were recorded before placing them in the glass Petri dish containing $50 \mathrm{ml}$ of water for an additional $24 \mathrm{~h}$ in the incubator. The samples were washed with $4 \mathrm{ml}$ of fresh water and discarded. The $54 \mathrm{ml}$ of water was evaporated and the glass Petri dish was placed in a desiccator before weighing.

The difference between the original mass of the shallow dish and its final mass was calculated to deduce the percentage of the original mass loss of the specimen.

\section{Radiopacity}

Root canal sealer specimens, $10 \mathrm{~mm}$ in diameter and $1 \mathrm{~mm}$ high, were prepared and allowed to set before placing them on an X-ray film with an aluminum step wedge (1-9 mm). A $70 \mathrm{kV}$ X-ray unit (Satelec, Merignac, France) was used for the exposure and all of the films were developed at the same time in an automatic developer. The $X$-rays were scanned.

The optical density of the samples was compared to that of the aluminium step wedges using an automatic program (Corel Photo Painting).

\section{Other clinically relevant properties}

\section{Eugenol leaching}

It was measured as described previously [11]. Determination of eugenol maximum excitation and emission wavelengths

A fluorescence spectrometer LS-3B (Perkin-Elmer Ltd, Buckinghamshire, England) equipped with a cell holder thermostated at $37^{\circ} \mathrm{C}$ was used. The apparatus excitation wavelength range was $270-720 \mathrm{~nm}$ and the emission wavelength range was 250 $800 \mathrm{~nm}$. Since, eugenol is barely water soluble at room temperature, it was first solubilized in 3-(4,5dimethylthiazol-2-yl)-2,(-diphenyl tetrazolium bromide) (DMSO) (Sigma, Chemical Company, St Louis, USA), then a $10 \mu \mathrm{M}$ eugenol solution was prepared in distilled water and used to determine its maximal excitation and emission wavelengths in a $4 \mathrm{ml}$ spectrometer cell. The eugenol maximal excitation wavelength was determined using the excitation mode. The fluorescence values were recorded over the entire excitation wavelength range. A spectrum was recorded using the wavelengths and the fluorescence values. In the same manner, the maximal emission wavelength was determined using the emission mode. The fluorescence values were also recorded over the entire emission wavelength range. A spectrum was established using the wavelengths and the fluorescence values.

Standard curve establishment

The excitation and emission mode (ex/em) was used to establish a standard curve between the fluorescence values recorded and the known eugenol concentrations $\left(10^{-1}-10^{-7} \mathrm{M}\right)$. A statistical linear relationship was sought between eugenol concentration and fluorescence by the method of the least squares at the $95 \%$ confidence level.

\section{Experimentation}

Twenty central maxillary incisors were used during this study. The crown was removed with a fissure bur on a highspeed handpiece under a water coolant. The patency of the apex was checked with $\mathrm{K}$ files \#15 to ensure that the apices of all of the teeth were permeable. The working length was determined by subtracting $1 \mathrm{~mm}$ from the actual root length. The root canals were prepared by the same operator with ProFiles (Maillefer Dentsply, Ballaigues, Switzerland) using a reduction 
handpiece powered by an electric motor following the sequence:

ProFile.taper $06 \# 30, \# 25$ and \#20

ProFile.taper $04 \# 25$ and \#20

ProFile.taper 06 \#20, \#25 and \#30

A K file \# 15 was used between each Profile to verify the apex patency.

Irrigant was $1 \% \mathrm{NaOCl}$ delivered with a 27 gauge needle, $2 \mathrm{ml}$ between each file size. The root canals were then filled by the lateral condensation of gutta-percha with one of the two sealers and the five powder/liquid ratios ( $n=4$ per group).

The two apical millimeters of the teeth were immediately placed for $24 \mathrm{~h}$ at $37^{\circ} \mathrm{C}$ in contact with $1 \mathrm{ml}$ phosphate buffered saline (PBS) containing penicillin $50 \mathrm{IU} / \mathrm{ml}$ and streptomycin $50 \mu \mathrm{g} / \mathrm{ml}$. This was carried out 1 day after filling as well as after storage of the teeth for an additional day, and then for 1 month without renewing the buffer at $37^{\circ} \mathrm{C}$. The teeth were stored in closed vials because eugenol is volatile. The concentration of eugenol that diffused from the sealer into the PBS was measured by spectrofluorimetry.

\section{Sealing properties}

The dye extraction method was used to record the sealing properties of the five groups $12 \mathrm{~s}$. The 20 roots were covered with two layers of nail varnish except for the last apical millimeter. The apex of the teeth were dipped in glass vials for $24 \mathrm{~h}$ at $37^{\circ} \mathrm{C}$ in a neutral buffered $2 \%$ methylene blue solution, under normal atmospheric pressure. After removal from the dye, the teeth were rinsed under tap water for 30 min and the varnish was removed with polishing disks mounted on a handpiece. The roots were then stored in a hermetically sealed vial containing $600 \mu \mathrm{l}$ of concentrated (65 wt\%) nitric acid for 3 days. The vials were then centrifuged at $14,000 \mathrm{rpm}$ for $5 \mathrm{~min}$ to separate gutta-percha debris from the extracted dye. Two hundred milliliter of the supernatant were taken from each vial and transferred to a 96-well plate. The absorbance of the 96-well plate was determined using an automatic microplate spectrophotometer (E 960, Bioblock, Strasbourg, France) at $550 \mathrm{~nm}$ using concentrated nitric acid as the blank.

\section{Statistical analysis}

For The Cortisomol and the Pulp Canal Sealer EWT, an analysis of variance, at the $95 \%$ confidence level, was used to evaluate the influence of the powder/liquid ratio. For the Cortisomol, a Duncan's multiple range test was used to compare the three consistencies.

\section{Results}

\section{Powder/liquid ratio}

\section{Cortisomol}

The manufacturer recommends a powder/liquid ratio of 2.8 .

The mean powder/liquid ratio was $3.1 \pm$ $1.8 \mathrm{~g} / \mathrm{l}$ with $95 \%$ of the values between 2 and 4.50. Three consistencies were determined: liquid consistency at a powder/liquid ratio of 2 , a medium consistency at a powder/liquid ratio of 2.8 and a thick consistency at a powder/liquid ratio of 4.5.

\section{Pulp Canal Sealer EWT}

The manufacturer recommends a powder/liquid ratio of four.

The mean powder/liquid ratio was $5.7 \pm 1.2 \mathrm{~g} / \mathrm{l}$ with $95 \%$ of the values between 4 and 6 . Only two consistencies were determined thanks to a lower discrepancy of the powder/liquid ratios: medium consistency at a powder/liquid ratio of four and a thick consistency at a powder/liquid ratio of six.

\section{ISO standards results}

\section{Flow}

\section{Cortisomol}

The analysis of variance showed that an increased powder/liquid ratio statistically reduced the flow of Cortisomol $(p<0.001)$. The Duncan test showed three different groups: the disc obtained with the powder/liquid ratio two was statistically larger than that obtained with the powder/ liquid ratio 2.8, which in turn was larger than that obtained with the powder/liquid ratio 4.5 (Table 1). Only the fluid consistency met the ISO requirements.

\section{Pulp Canal Sealer EWT}

The analysis of variance showed a statistical difference between the two powder/liquid ratios of Pulp Canal Sealer EWT $(p<0.001)$ : the powder/liquid ratio five produced a larger disk than the powder/liquid ratio six. Only the medium consistency met the ISO requirements.

\section{Working time Cortisomol}

The analysis of variance showed a statistical difference among the working times $(p<0.001)$. 
Table 1 Influence of the powder/liquid ratio on the flow of two zinc oxide-eugenol-based root canal sealers.

\begin{tabular}{ll}
\hline & Flow in mm (SD) \\
\hline ISO standards 6876 & $20 \mathrm{~mm}$ minimum \\
Cortisomol P/L 2 & $21.2(0.8)^{\mathrm{a}}$ \\
Cortisomol P/L 2.8 & $17(0.7)^{\mathrm{b}}$ \\
Cortisomol P/L 4.25 & $15(0.7)^{\mathrm{c}}$ \\
Cortisomol manufacturer data & 31 \\
Pulp Canal Sealer EWT P/L 5 & $20(0.8)^{\mathrm{a}}$ \\
Pulp Canal Sealer EWT P/L 8 & $15.2(0.5)^{\mathrm{b}}$ \\
Pulp Canal Sealer EWT manufacturer data & $40 \mathrm{~mm}$ \\
\hline
\end{tabular}

The analysis of variance showed a statistical difference among the groups for Cortisomol $(p<0.01)$ and Pulp Canal Sealer EWT. The Duncan test showed a statistical difference between the subgroups with a different superscript letter $(p<0.05)$.

The Duncan test showed three different subgroups corresponding to the three consistencies $(p<0.05)$ (Table 2).

\section{Pulp Canal Sealer EWT}

No statistical difference was found between the two working times (ns).

\section{Setting time}

\section{Cortisomol}

The analysis of variance showed a statistical difference among the setting times $(p<0.001)$. The Duncan test showed three different subgroups corresponding to the three consistencies $(p<0.05)$ (Table 3).

Table 2 Influence of the powder/liquid ratio on the working time of two zinc oxide-eugenol- based root canal sealers.

\begin{tabular}{|c|c|}
\hline & Working time (SD) \\
\hline ISO standards 6876 & $\begin{array}{l}\text { Minimum } 90 \% \text { of } \\
\text { the manufacturer data }\end{array}$ \\
\hline Cortisomol P/L 2 & $26(4) \min ^{\mathrm{a}}$ \\
\hline Cortisomol P/L 2.8 & $33(6) \min ^{\mathrm{b}}$ \\
\hline Cortisomol P/L 4.25 & $50(8) \min ^{c}$ \\
\hline $\begin{array}{l}\text { Cortisomol manufacturer } \\
\text { data }\end{array}$ & $30-60 \mathrm{~min}$ \\
\hline $\begin{array}{l}\text { Pulp Canal Sealer } \\
\text { EWT P/L } 5\end{array}$ & $5-\mathrm{h}(10) \mathrm{min}$ \\
\hline $\begin{array}{l}\text { Pulp Canal Sealer } \\
\text { EWT P/L } 8\end{array}$ & $5-\mathrm{h}(20) \mathrm{min}$ \\
\hline $\begin{array}{l}\text { Pulp Canal Sealer EWT } \\
\text { Manufacturer data }\end{array}$ & $6-8 h$ \\
\hline
\end{tabular}

The analysis of variance showed a statistical difference for Cortisomol $(p<0.001)$. The Duncan test showed three different subgroups indicated with different superscript letters. No difference was found for Pulp Canal Sealer EWT (ns).
Table 3 Influence of the powder/liquid ratio on the setting time of two zinc oxide-eugenol-based root canal sealers.

\begin{tabular}{ll}
\hline & Setting time (SD) \\
\hline ISO standard 6876 & $30 \mathrm{~min}$ to $72 \mathrm{~h}$ \\
Cortisomol P/L 2 & $110 \mathrm{~min}(24) \mathrm{min}^{\mathrm{a}}$ \\
Cortisomol P/L 2.8 & $176(32) \mathrm{min}^{\mathrm{b}}$ \\
Cortisomol P/L 4.25 & $260(35) \mathrm{min}^{\mathrm{c}}$ \\
Cortisomol manufacturer data & $165 \mathrm{~min}$ \\
Pulp Canal Sealer EWT P/L 4 & $121(21) \mathrm{min}$ \\
Pulp Canal Sealer EWT P/L 6 & $143(27) \mathrm{min}$ \\
Pulp Canal Sealer EWT manufacturer data & $90 \mathrm{~min}$
\end{tabular}

The analysis of variance showed a statistical difference for Cortisomol $(p<0.001)$. The Duncan test showed three different subgroups indicated with different superscript letters. No difference was found for Pulp Canal Sealer EWT (ns).

\section{Pulp Canal Sealer EWT}

No statistical difference was found between the two setting times (ns).

\section{Film thickness}

Cortisomol

No statistical difference was found among the three thickness (ns) (Table 4).

Pulp Canal Sealer EWT

The analysis of variance showed a difference between the two thicknesses $(p<0.001)$. The thick consistency led to a film thickness exceeding the ISO requirements.

\section{Dimensional change}

\section{Cortisomol}

No statistical difference was found among the three dimensional changes (ns) (Table 5). The liquid

\begin{tabular}{ll}
$\begin{array}{l}\text { Table } 4 \text { Influence of the powder/liquid ratio on the film } \\
\text { thickness of two zinc oxide-eugenol- based root canal sealers. }\end{array}$ \\
$\begin{array}{ll}\text { Film thickness } \\
\text { in } \mu \mathrm{m} \text { (SD) }\end{array}$ \\
\hline ISO standards 6876 & $50 \mu \mathrm{m}$ maximum \\
Cortisomol P/L 2 & $36(4.5)$ \\
Cortisomol P/L 2.8 & $37.8(6.0)$ \\
Cortisomol P/L 4.25 & $41.4(4.4)$ \\
Cortisomol manufacturer data & 32 \\
Pulp Canal Sealer EWT P/L 5 & $32(6)^{\mathrm{a}}$ \\
Pulp Canal Sealer EWT P/L 8 & $78(12)^{\mathrm{b}}$ \\
Pulp Canal Sealer EWT manufacturer data & $<50$
\end{tabular}

The analysis of variance showed a statistical difference for Pulp Canal Sealer EWT $(p<0.001)$. No difference was found for Cortisomol (ns). 
Table 5 Influence of the powder/liquid ratio on the dimensional changes of two zinc oxide-eugenol-based root canal sealers.

\begin{tabular}{ll}
\hline & $\begin{array}{c}\text { Dimensional } \\
\text { changes in \% }\end{array}$ \\
\hline ISO standards 6876 & $99<$ dimension \\
& $<100.1$ \\
Cortisomol P/L 2 & 101 \\
Cortisomol P/L 2.8 & 101 \\
Cortisomol P/L 4.25 & 100 \\
Cortisomol manufacturer data & Non-given \\
Pulp Canal Sealer EWT P/L 5 & 100 \\
Pulp Canal Sealer EWT P/L 8 & 100 \\
Pulp Canal Sealer EWT & Non-given \\
Manufacturer data &
\end{tabular}

No statistical difference was found for Cortisomol or Pulp Canal Sealer EWT.

and medium consistencies showed a dimensional change that did not meet the ISO requirements.

\section{Pulp Canal Sealer EWT}

No statistical difference was found between the two dimensional changes (ns).

\section{Solubility}

\section{Cortisomol}

The analysis of variance showed a statistical decrease in solubility with an increased powder/liquid ratio $(p<0.001)$. The Duncan test showed three subgroups corresponding to the three consistencies $(p<0.05)($ Table 6$)$.

\section{Pulp Canal Sealer EWT}

No statistical difference was found between the two solubilities (ns).

\begin{tabular}{lc}
$\begin{array}{l}\text { Table } 6 \text { Influence of the powder/liquid ratio on the } \\
\text { solubility of two zinc oxide-eugenol-based root canal sealers. }\end{array}$ \\
$\begin{array}{ll}\text { Solubility in } \\
\%(S D)\end{array}$ \\
\hline ISO standards 6876 & 3 maximum \\
Cortisomol P/L 2 & $0.57(0.12)^{\mathrm{a}}$ \\
Cortisomol P/L 2,8 & $0.43(0.11)^{\mathrm{b}}$ \\
Cortisomol P/L 4,25 & $0.19(0.04)^{\mathrm{C}}$ \\
Cortisomol manufacturer data & 0.16 \\
Pulp Canal Sealer EWT P/L 5 & $0.07(0.01)$ \\
Pulp Canal Sealer EWT P/L 8 & $0.05(0.01)$ \\
Pulp Canal Sealer EWT manufacturer data & 0.31
\end{tabular}

The analysis of variance showed a statistical difference for Cortisomol $(p<0.001)$. The Duncan test showed three different subgroups indicated with different superscript letters. No difference was found for Pulp Canal Sealer EWT (ns).
Table 7 Influence of the powder/liquid ratio on the radiopacity of two zinc oxide-eugenol-based root canal sealers.

$\mathrm{mm}$ aluminum (SD)

ISO standardsn 6876

Cortisomol P/L 2

Cortisomol P/L 2.8

$3 \mathrm{~mm}$ minimum

Cortisomol P/L 4.25

$5.1(0.5)^{\mathrm{a}}$

$5.9(0.6)^{\mathrm{b}}$

Cortisomol manufacturer data

$9.1(0.6)^{\mathrm{c}}$

$>3$

Pulp Canal Sealer EWT P/L $4 \quad 7.4(0.5)^{\mathrm{a}}$

Pulp Canal Sealer EWT P/L $6 \quad 8.6(0.7)^{\mathrm{b}}$

Pulp Canal Sealer EWT manufacturer data $>3$

The analysis of variance showed a statistical difference for Cortisomol as well as for Pulp Canal sealer EWT $(p<0.001)$. The Duncan test showed different subgroups indicated with different superscript letters.

\section{Radiopacity}

\section{Cortisomol}

The analysis of variance showed a statistical difference among the three groups $(p<0.001)$ (Table 7). The Duncan test showed that the higher the powder/liquid ratio, the higher the radiopacity $(p<0.05)$.

\section{Pulp Canal Sealer EWT}

The analysis of variance showed that a higher powder/liquid ratio gave a higher radiopacity $(p<$ 0.001).

\section{Other clinically relevant properties}

\section{Eugenol leaching}

Correlation between eugenol concentration and fluorescence

A statistically significant correlation was found $(p<$ 0.001 ) with a correlation coefficient $R^{2}$ of 0.98 .

Cortisomol

The analysis of variance showed a statistical difference among the groups at 1 day $(p<0.02)$,

Table 8 Concentration of eugenol released, in $1 \mathrm{ml}$ of phosphate buffered saline, from roots filled with guttapercha and a zinc oxide-eugenol-based sealer $\left(10^{-5} \mathrm{M}\right)$.

\begin{tabular}{llll}
\hline Sealer & 1 day (SD) & 2 days (SD) & 1 month (SD) \\
\hline Cortisomol P/L 2 & $1.00(0.26)^{\mathrm{a}}$ & $0.53(0.19)^{\mathrm{a}}$ & $0.90(0.34)^{\mathrm{a}}$ \\
Cortisomol P/L 2.8 & $0.95(0.07)^{\mathrm{a}}$ & $0.40(0.26)^{\mathrm{a}}$ & $0.71(0.16)^{\mathrm{a}}$ \\
Cortisomol P/L 4.5 & $0.35(0.17)^{\mathrm{b}}$ & $0.21(0.05)^{\mathrm{b}}$ & $0.46(0.10)^{\mathrm{b}}$ \\
Pulp Canal Sealer & $0.46(0.10)$ & $0.31(0.04)$ & $0.95(0.26)^{\mathrm{a}}$ \\
EWT P/L 4 & & & \\
Pulp Canal Sealer & $0.52(0.19)$ & $0.24(0.03)$ & $0.43(0.22)^{\mathrm{b}}$ \\
EWT P/L 6 & & &
\end{tabular}

Within the same sealer, the subgroups belonging to the same column, with a different superscript letter are statistically different. 
Table 9 Apical sealing efficiency of two zinc oxide-eugenolbased root canal sealers measured by the dye extraction method.

\begin{tabular}{ll}
\hline Sealer & Optical density (SD) \\
\hline Cortisomol P/L 2 & $0.26(0.10)$ \\
Cortisomol P/L 2.8 & $0.30(0.12)$ \\
Cortisomol P/L 4.5 & $0.24(0.14)$ \\
Pulp Canal Sealer EWT P/L 4 & $0.32(0.15)$ \\
Pulp Canal Sealer EWT P/L 6 & $0.27(0.15)$ \\
\hline
\end{tabular}

2 days $(p<0.04)$ and 30 days $(p<0.04)$ (Table 8$)$. The Duncan test showed that a thicker consistency reduced the amount of released eugenol $(p<0.05)$. Pulp Canal Sealer EWT

The analysis of variance failed to show a difference between the two groups at 1 day and 2 days but showed a lower eugenol concentration with a high powder/liquid ratio at 30 days $(p<0.02)$.

\section{Sealing properties}

\section{Cortisomol}

The analysis of variance did not show any statistical difference among the groups (ns) (Table 9).

Pulp Canal Sealer EWT

The analysis of variance did not show any statistical difference between the groups (ns)

\section{Discussion}

In this study we investigated the effects of modifications to the powder/liquid ratio by endodontists on the physical properties recommended by ISO standards as well as on other clinically relevant properties of the zinc oxide-eugenol-based root canal sealers.

The preliminary results of this study confirm previous works [6]: different endodontists use the same root canal sealer at different consistencies corresponding to their clinical habits. Endodontists usually use a powder/liquid ratio higher than that is recommended by the manufacturer. The discrepancy among the powder/liquid ratios was higher with the Cortisomol than with the Pulp Canal Sealer EWT, which lead us to build three groups for the Cortisomol and two the for Pulp Canal Sealer EWT. What are the effects of these variations on the properties of the root canal sealers?

The flow properties and film thickness represent the ability of a sealer to change form, to completely fill the prepared root canal system. Root canal sealers, like many cements, are non-Newtonian materials [13]. These pseudoplastic materials are thixotropic, i.e. their viscosity-shear rate decreases with stress. This property presents advantages in endodontics because a thick root canal sealer prevents the adequate insertion of the gutta-percha master cone [14]. The zinc oxideeugenol-based sealers display good flow properties compared to other families of root canal sealers [15]. Nevertheless, as already shown [16], a higher powder/liquid ratio statistically decreased the flow properties of both sealers, and increased the film thickness of the Pulp Canal Sealer EWT. This might have led to clinical consequences, but our study showed no statistical difference among the sealing efficiencies of the sealers. In addition, all of the filling techniques use a compacted gutta-percha core that spreads the root canal sealer between the dentinal walls and the gutta-percha. Since, the pressure transmitted by gutta-percha to a viscous sealer is higher than to a liquid sealer [17], the thixotropic properties of the sealer counterbalance the decrease in flow properties. The pressure transmitted by the gutta-percha core decreases the thickness of the root canal sealer, and it is known that thin layers of Pulp Canal Sealer EWT lead to a better apical seal than thick layers [18]. This also can be related to the considerable creep of zinc oxide-eugenol-based dental cements, compared to other dental cements [19].

The working time corresponds to the period of time during which it is possible to manipulate the sealer without altering its properties, and should be as long as possible. The setting time is the time necessary for the sealer to achieve its definitive properties and should be as short as possible, because it is very difficult to maintain the dryness of the empty prepared canal. The setting time of the zinc oxide-eugenol-based sealers varies greatly according to different parameters: the conditions of the experimentation (e.g. temperature, humidity) [8], the additional components of the sealer such as the resin [20], the type of zinc oxide $^{2}$ and the size of the particles [21]. An increased powder/liquid ratio increased the working time as well as the setting time only for Cortisomol. Excess zinc oxide particles may react with the released eugenol giving a new zinc eugenolate. This additional reaction also leads to a lower concentration of eugenol released when the powder/liquid ratio increases. Pulp Canal Sealer EWT contains resin to increase the adhesion to dentin and improve the mechanical properties of the sealer [22], and to control the setting reaction [20]. The resin controls the speed of the setting reaction and may counterbalance the presence of additional zinc oxide particles, explaining the lack of effect of an increased powder/liquid ratio on both the working time 
and the setting time of Pulp Canal Sealer EWT. In any case, the smallest recorded working time is 26 min for Cortisomol, which is more than enough to fill any root canal. Thus, the recorded influence of the powder/liquid ratio on the working and setting times of Cortisomol is clinically irrelevant.

Since, the sealer contributes to bond the guttapercha to the dentinal walls, it should be as stable as possible. The ISO standards recommend a maximum retraction of $1 \%$ associated to a maximum expansion of $0.1 \%$. Nobody knows if these requirements rely on clinical observations. If the apex of a tooth is $30 / 100 \mathrm{~mm}$ wide and filled with sealer alone, and a $1 \%$ retraction means a $3 \mu \mathrm{m}$ retraction of the total mass, does it have clinical consequences? The Pulp Canal Sealer EWT displayed good dimensional stability and low solubility, whatever its consistency. This may be related to the presence of resin in its composition that protects the zinc eugenolate from dissolution [22]. This is far from the Bandyopathy's results which showed dimensional changes as high as $10 \%$ [23], but the results were obtained after 30 minutes and the sealer was in contact with the water of the dilatometer. On the other hand, these results corroborate previous works [24,25] which showed good dimensional stability of this sealer. Cortisomol showed higher dimensional changes than the Pulp Canal Sealer EWT, but this remains acceptable. Cortisomol showed a decrease of the solubility of the sealer with an increased powder/ liquid ratio. The presence of additional zinc oxide particles in the set sealer seems to prevent its dissolution, which is consistent with the lower eugenol release observed with a high powder/ liquid ratio. The released eugenol may react immediately with available zinc oxide particles, preventing the loss of both components.

The sealer must be radiopaque in order to be able to evaluate the quality of the root canal fillings and to monitor the resorption of the sealers in cases of overfilling [26]. The radiopacity of a $1 \mathrm{~mm}$ thick mineralised tissue is equivalent to that of $1 \mathrm{~mm}$ of aluminium [27]. Therefore, the radiopacity of $3 \mathrm{~mm}$ of aluminum, as requested by the ISO standards, corresponds to $2 \mathrm{~mm}$ of cortical bone $+1 \mathrm{~mm}$ of marrow bone. Under these conditions, it is obvious that a $3 \mathrm{~mm}$ aluminum radiopacity should be considered as a minimum [28]. Both sealers showed an increased radiopacity with an increased powder/liquid ratio. The radiopacity of Cortisomol is due to the presence of lead oxide and that of Pulp Canal Sealer EWT is related to the presence of silver. Thus, as expected, an increased powder/liquid ratio corresponds to a higher concentration of a radiopaque material in the set sealer.

An increased powder/liquid ratio reduced the amount of released eugenol at $1 \mathrm{~d}, 2 \mathrm{~d}$ and 1 month for the Cortisomol and at 1 month for the Pulp Canal Sealer EWT. This does not correspond to Wilson's results which recorded the elution of eugenol from 13 different zinc oxide-eugenol cements [7], but all of the sealers he used had different compositions making the comparison invalid. Thus, we can assume that it is a general trend of the material: the higher the powder/liquid ratio, the lower the eugenol release. The supplementary zinc oxide particles probably bound the eugenol as fast as it is released, thus only the outer surface of the sealer is prone to eugenol release. It is worth noticing that the rate of release decreases rapidly over time [29], and that the concentrations remain within clinically acceptable limits, around $10^{-5} \mathrm{M}$ where eugenol presents anti-inflammatory properties [30]. The amount of eugenol released depends on the filling technique [11].

The method used for the evaluation of the apical leakage has shown to be one of the most reliable [12,31]. The sealing efficiency, at one month, of both sealers was not modified by the variation in the powder/liquid ratio. This lack of influence of the powder/liquid ratio on the sealing properties of the zinc oxide-eugenol-based sealers is probably due to the very small amounts of sealer used, associated to the fact that straight canals were used for this in vitro study. Since very thin layers of sealers are necessary to achieve a bond between the gutta-percha core and the dentinal walls, a $1 \%$ variation in dimensional stability has no effect on the apical seal. A thick consistency might have lead to a wrong setting of the master cone in a curved thin canal, altering the outcome of the study.

Under the conditions of this study, it seems that variations in the powder/liquid ratio of zinc oxide-eugenol-based root canal sealers have a limited influence on the properties of the sealers, varying according to the brand of the sealer. Only three properties are equally altered by variations in the powder/liquid ratio for both sealers: the flow is decreased by $25 \%$, the radiopacity is increased by $40 \%$ and the amount of released eugenol is decreased by $50 \%$. In addition, these alterations to their properties are likely to be clinically irrelevant. Therefore we can conclude that the endodontists can prepare the zinc oxideeugenol-based root canal sealers at their chosen consistency according to the filling technique they use. 


\section{References}

[1] Wilson AD, Mesley RJ. Zinc oxide-eugenol cements III: infrared spectroscopic studies. J Dent Res 1972;51:1581-8.

[2] Prosser HJ, Wilson AD. Zinc oxide eugenol cements. VI. Effect of zinc oxide type on the setting reactions. J Biomed Mater Res 1982;16:585-98.

[3] Crisp S, Amberseley M, Wilson AD. Zinc oxide-eugenol cements $\mathrm{V}$ : instrumental studies of the catalysis and acceleration of the setting reaction. J Dent Res 1980;59: 44-54.

[4] Crisp S, Jennings MA, Wilson AD. A study of temperature changes in setting dental cements. J Oral Rehab 1978;5: 139-44.

[5] Wilson AD, Clinton DJ, Miller RP. Zinc oxide-eugenol cements IV: microstructure and analysis. J Dent Res 1973; 52:253-60.

[6] Halimi P, Camps J, Proust JP, Roche M. Etude des propriétés physico-chimiques de 4 ciments de scellement endodontiques. Rev Fr Endod 1990;9:35-42.

[7] Wilson AD, Batchelor RF. Zinc oxide-eugenol cements II: study of erosion and disintegration. J Dent Res 1970;49: 593-8.

[8] Batchelor RF, Wilson AD. Zinc oxide-eugenol cements I: The effects of atmospheric conditions on rheological properties. J Dent Res 1969;48:883-7.

[9] Miserendino LJ. Instruments, materials and devices. In: Cohen S, Burns RC, editors. Pathways of the Pulp, Vlth ed. St Louis, USA: Mosby; 1996. p. 377-416.

[10] International Standard Organisation 6876. 2001 Dental rootcanal sealing materials. Geneva, Switerland.

[11] Abou Hashieh I, Pommel L, Camps J. Concentration of eugenol apically released from zinc oxide-eugenol-based sealers. J Endodon 1999;25:713-5.

[12] Camps J, Pashley D. Reliability of the dye penetration studies. J Endodon 2003;29:592-4.

[13] Uhrich JM, Moser JB, Heuer MA. The rheology of selected root canal cements. J Endodon 1978;4:373-9.

[14] Orstavik D. Seating of gutta-percha points: effects of sealers with varying thickness. J Endodon 1982;8:213-8.

[15] Ono K, Mastumoto K. Physical properties of $\mathrm{CH} 61$, a newly developed root canal sealer. J Endodon 1998;24:244-7.

[16] Orstavik D. Physical properties of root canal sealers: measurement of flow, working time, and compressive strength. Int Endod J 1983;16:99-107.
[17] Brooke KK, Grace MA. Relationship of intracanal pressure with viscosity of endodontic sealer during warm guttapercha vertical compaction. Oral Surg, Oral Med, Oral Pathol, Oral Radio Endod 2000;89:618-22.

[18] Georgopoulou MW, Wu MK, Nikolaou A, Wesselink P. Effect of thickness on the sealing ability of some root canal sealers. Oral Surg, Oral Med, Oral Pathol, Oral Radio Endod 1995;80:338-44.

[19] Wilson AD, Lewis BG. The flow properties of dental cements. J Biomed Mater Res 1980;14:383-91.

[20] Grossman LI. The effect of pH of rosin on setting time of root canal sealers. J Endodon 1982;8:326-7.

[21] Norman RD, Phillips RW, Swartz ML, frankiewitcz T. The effect of particle size on the physical properties of zinc oxide-eugenol mixtures. J Dent Res 1964;43:252-62.

[22] Sousa-Neto MD, Guimarães LF, Saquy PC, Pecora JD. Effect of different grades of gum rosins and hydrogenated resins on the solubility, disintegration, and dimensional alterations of Grossman cement. J Endodon 1999;25:477-80.

[23] Bandyopadhay S. A study of the volumetric setting shrinkage of some dental materials. J Biomed Mater Res 1982;16: 135-44.

[24] Mc Comb D, Smith DC. Comparison of physical properties of polycarboxylate-based and conventional root canal sealers. J Endodon 1976;8:228-35.

[25] Orstavik D, Nordahi I, Tibballs JE. Dimensional change following setting of root canal sealer materials. Dent Mater 2001;17:512-9.

[26] Beyer-Olsen EM, Orstavik D, Eriksen HM. Radiographic voids and leakage along root fillings in vitro. Int Endod J 1983;16: 51-8.

[27] Manson-Hing LR. An investigation of the roetgengraphic contrast of enamel, dentine and aluminium. Oral Surg, Oral Med, Oral Pathol 1961;14:1456-72.

[28] Beyer-Olsen EM, Orstavik D. Radioopacity of root canal sealers. Oral Surg, Oral Med, Oral Pathol 1981;51:320-8.

[29] Hume WR. An analysis of the release and the diffusion through dentin of eugenol from zinc oxide-eugenol mixtures. J Dent Res 1984;63:881-4.

[30] Markowitz K, Moynihan M, Liu M, Kim S. Biological properties of eugenol and zinc oxide-eugenol. Oral Surg, Oral Med, Oral Pathol 1992;73:729-37.

[31] Pommel L, Jaquot B, Camps J. Lack of correlation among three method for evaluation of apical leakage. J Endodon 2001;27:347-50. 